\title{
A Competição Ter, Haver e Existir na Escrita Escolar
}

The Competition Ter, Haver and Existir in the Scholar Written

Elyne Giselle de Santana Lima Aguiar VITÓRIO *

Resumo: Tendo em vista que, no português brasileiro, ter é o verbo existencial selecionado na fala, mas, na escrita, haver é o existencial canônico e existir, devido ao seu caráter de verbo existencial substantivo, tende a apresentar um percentual de uso baixo e constante, descrevemos e analisamos as construções existenciais formadas com os verbos ter, haver e existir na escrita de alunos dos ensinos fundamental, médio e superior da cidade de Maceió-AL. Para tanto, seguimos os pressupostos teórico-metodológicos da Teoria da Variação e Mudança (WEINREICH; LABOV; HERZOG, 2006; LABOV 2008), associados a estudos linguísticos sobre as construções existenciais no português brasileiro (AVELAR, 2006a; MARINS, 2013; VITÓRIO, 2014) e utilizamos, para a análise estatística dos dados, o programa computacional GOLDVARB $\mathrm{X}$. De acordo com os resultados obtidos, verificamos que há uma competição acirrada entre ter e haver e uma baixa frequência de uso de existir, sendo essa variação condicionada pelos grupos de fatores traço semântico do argumento interno, escolaridade e tema da produção textual, com o verbo ter sendo mais frequente quando o argumento interno apresenta o traço [+ concreto], na escrita de alunos menos escolarizados e quando o tema da produção textual está relacionado a experiências pessoais dos alunos.

Palavras-chave: Construções existenciais. Língua escrita. Variação linguística.

\footnotetext{
* Doutora em Linguística pela Universidade Federal de Alagoas (2012). Professora da Universidade Federal de Alagoas - Campus Sertão - UFAL, Maceió - AL. Contato: elyne.vitorio@gmail.com.
} 
Abstract: Considering that, in Brazilian Portuguese, "ter" is the existential verb selected by the speech, but in the written, "haver" is the canonical existential verb and "existir", due its character of noun existential verb and hence trend to present a low and constant percentual use, we describe and analyze the existential constructions build with the verbs "ter", "haver" and "existir" in the written of Elementary, High School and College students in the city of Maceió/AL. In order to do that, we follow the theoretical and methodological basis of the Theory of Variation and Change (WEINREICH; LABOV; HERZOG, 2006; LABOV 2008), joint with linguistic studies in the Brazilian Portuguese (AVELAR, 2006a; MARINS, 2013; VITÓRIO, 2014) and we use, for the statistical analysis of data, the software GOLDVARB X. According with the results, we verify that there is a tight competition between "ter" and "haver" and a low frequency of "existir", and this variation is conditioned by the groups of factors semantic trace of the internal argument, scholarity and the textual production theme, with the verb "ter" being more often used when the internal argument presents the trace [+ concrete], in the written of less educated and when the textual production theme is related with the personal experience of the students.

Keywords: Existential constructions. Written language. Linguistics variation.

\section{Introdução}

Tendo em vista que, no português brasileiro falado, ter é o verbo existencial selecionado (CALLOU; AVELAR, 2000; DUARTE, 2003; MARTINS; CALLOU, 2003; VITÓRIO, 2012), mas, no português brasileiro escrito, haver é o verbo existencial canônico (CALLOU; DUARTE, 2005; VITÓRIO, 2013) e existir, devido ao seu caráter de verbo existencial substantivo (AVELAR, 2006a), tende a apresentar uma frequência de uso baixa e constante tanto na fala quanto na escrita (MARINS, 2013; VITÓRIO, 2014), descrevemos e analisamos, neste trabalho, as construções existenciais formadas com os verbos ter, haver e existir na escrita escolar.

Nosso objetivo é não só analisar a frequência de uso desses verbos e os grupos de fatores linguísticos e/ou sociais que favorecem e desfavorecem 
as realizações dessas construções existenciais na escrita escolar, mas também verificar se as realizações encontradas em dados de língua falada (Cf. VITÓRIO, 2014) são utilizadas durante o processo de escolarização e, ao mesmo tempo, refletir sobre a forma como a língua escrita tende a recuperar formas linguísticas que já não fazem parte dos dados que as crianças estão expostas durante o processo de aquisição da linguagem (KATO, 1996).

Para a descrição e análise dos dados, propomos as seguintes questões: qual a frequência de uso dos verbos ter e haver e como se comporta o verbo existir nesse contexto variável? Que variáveis linguísticas e/ou sociais motivam as realizações dessas construções? Qual o papel da escola na recuperação e manutenção do verbo haver, tendo em vista que, na língua falada, ter é o verbo existencial preferido?

Como respostas provisórias às questões acima formuladas, acreditamos não só que haver será o verbo existencial selecionado, mostrando, assim, que as normas convencionais da escrita reprimem as inovações da fala e fazem o falante voltar às formas eliminadas, ou no limiar do desaparecimento (Cf. KATO, 1996), como também que tal variação será motivada pelos grupos de fatores tema da produção, tempo verbal, traço semântico do argumento interno, sexo e escolaridade, com a variável escolaridade exercendo um papel importante na recuperação e manutenção do verbo haver.

Nosso trabalho está organizado da seguinte forma: nas seções 1 e 2 , apresentamos os pontos que serviram de base para o desenvolvimento deste estudo; em seguida, na seção 3, apresentamos o quadro teórico que norteia esta pesquisa; na seção 4, caracterizamos os dados analisados e a amostra utilizada neste trabalho; por fim, na seção 5, descrevemos e analisamos os resultados obtidos, mostrando, primeiramente, os dados alcançados para a variável dependente e, em seguida, os grupos de fatores estatisticamente significativos na análise.

\section{A Supressão de Haver e a Emergência de Ter em Contextos Existenciais}

No português brasileiro, ter é o verbo existencial prototípico na fala, mas, na escrita, haver é o existencial selecionado. Para explicar a supressão de haver a emergência de ter em contextos existenciais, Avelar (2006a) argumenta 
que a baixa frequência de havere as restrições ao seu uso em alguns contextos existenciais, como em Tem/*Há gente que detesta ir à praia, decorrem de uma mudança na funcionalidade desse verbo. $O$ verbo haver teria deixado de compor o acervo de itens funcionais e migrado sua matriz para o acervo de itens substantivos, residindo ao lado de itens como existir, acontecer, ocorrer.

Tal mudança levou haver a alguma forma de especialização semântica, caso que não ocorre com ter, que é semanticamente neutro, não sendo mais possível, no português brasileiro, falar em variação ter e haver como competição entre duas formas funcionais. A variação ter e haver seria “desencadeada pela 'alimentação’ da gramática periférica no processo de escolarização (em oposição a gramática nuclear, construída no processo natural de aquisição da linguagem [...]" (AVELAR, 2006b, p. 101, grifos nossos), não havendo, na gramática internalizada dos falantes, tal variação, com ter ocupando o posto de verbo existencial.

... existem, de um lado, construções existenciais canônicas, construídas com o verbo ter, de outro lado, aparecem construções existenciais mais gerais, de uso normalmente apresentacional, com verbos como haver, aparecer, acontecer, surgir, etc. Assim, não estamos diante de uma variação a ser capturada como um fato de gramática interna do falante, a sua gramática nuclear, mas simplesmente de um padrão frásico do português contemporâneo que elege como a sua forma verbal prototípica o verbo ter. No âmbito da gramática naturalmente internalizada, portanto, não existe variação entre dois verbos existenciais no português brasileiro, mas entre um padrão canônico de gerar uma sentença existencial, para qual se recorre a um verbo funcional, e outros padrões diferenciados, com valores semântico-pragmáticos diversos que se valem de verbos não-funcionais. (AVELAR, 2006b, p. 116).

Outro fato apontado pelo autor diz respeito à razão de haver ter tido sua condição alterada. Avelar (2006a) defende a ideia de que a supressão de haver e a emergência de ter em contextos existenciais se encaixam em um conjunto mais amplo de mudanças por que vem passando o português brasileiro. A entrada do verbo ter em contextos existenciais, que ocorreu em algum momento do século XIX, teve início entre os chamados "contextos 
opacos", ou seja, em construções interpretadas como existenciais pelos falantes do português brasileiro contemporâneo, mas que, na verdade, consistem em verdadeiras construções possessivas, conforme podemos observar na construção (1).

(1) ... e asim diserão elles doadores que tinhão e em caza tres crianças emgeitadas que elles criarão Manoel Jozeph Pascoal os quais emcomendão aos Religiozos seos herdeiros os tenhão debaixo de sua propteção e os dotrinem como filhos juntamente com os mamalucos forros que em sua caza tem, em fé do qual assim o outrogarão, ... - 1632

(Exemplo extraído de Avelar, 2006a, p. 65, grifos nossos).

Segundo o autor, para um falante do português europeu contemporâneo, essa construção seria interpretada como possessiva, sendo possível indicar um sujeito para ter - os Religiozos, mas, para um falante do português brasileiro contemporâneo, a interpretação preferencial e talvez a única seria existencial. O mesmo "equívoco" pode ocorrer quando um falante do português brasileiro contemporâneo se defronta com uma construção do tipo (2) pronunciada por um falante do português europeu contemporâneo, em que a sentença tinha uns bancos de madeira pode ter como sujeito nulo correferente uma tasca ou aquela tasca.

(2) ... e depois fomos para UMA TASCA, meu, que era espectacular. então é AQUELA TASCA que eu já te contei, que era: tipo u[...], uma garagenzinha, estás a ver, e tinha uns bancos de madeira, tipo, umas tábuas de madeira em cima de tijolos (Década de 90 / Faixa Etária 1 - Culto)

(Exemplo extraído de Avelar, 2006a, p. 67, grifos nossos).

Tendo em vista esses dados, Avelar (2006a) argumenta que tal “equívoco" está relacionado às restrições ao sujeito nulo. Com a redução do paradigma flexional no português brasileiro, o sistema perde a categoria pro-referencial, o que impossibilita ao falante atribuir uma interpretação possessiva ao sujeito nulo das sentenças formadas com ter pessoal, havendo, 
assim, uma reanálise das construções possessivas em construções existenciais, uma vez que estas dispensam a instanciação de um sujeito pleno e, em seguida, a perda de pro-expletivo contribui para a supressão de haver no sistema linguístico.

Avelar (2006a) ainda observa o fato de que, ao contrário das crianças portuguesas que aos dois anos de idade apresentam sentenças existenciais construídas com o verbo haver, as crianças brasileiras até os três anos de idade não apresentam tais construções, sendo suas existenciais construídas exclusivamente com ter, o que o leva a argumentar que haver em construções existenciais só passaria a fazer parte do acervo linguístico das crianças brasileiras após o contato com a escola, ou seja, durante o processo de aprendizagem da língua escrita.

Tendo em vista a observação de Avelar (2006a), Vitório (2010) analisa as realizações de ter e haver na fala de crianças alagoanas entre 7 e 12 anos de idade e observa que, enquanto ter é o verbo existencial selecionado, apresentando um percentual de $96 \%$ versus $4 \%$ de haver, as parcas realizações de haver são restritas a construções em que as crianças retomam a fala do adulto, conforme podemos observar nos exemplos abaixo, o que a leva a argumentar que haver só deva fazer parte do repertório linguístico dos falantes a partir do processo de escolarização, indicando, assim, que haver, no português brasileiro, é um verbo existencial da escrita.

(3) L1: e houve castigo?

L2: houve não - a Tia Anali mandou a gente alimpá (C1L2L219M)

(4) L1: e houve castigo?

L2: houve (C1L3L485M)

(Exemplos extraídos de Vitório, 2010, p. 60, grifos nosso)

Esses dados nos permitem supor não só que, no âmbito da gramática nuclear das crianças aqui analisadas, a variação ter/haver existenciais é quase nula, como também que a criança acionou a mudança na direção de ter existencial e que a escola tenta reverter essa inovação através do processo de ensino/aprendizagem. A ideia que defendemos é a de que o verbo haver existencial provavelmente só deva ser adquirido realmente quando a criança entra em contato com a aprendizagem da língua escrita. (VITÓRIO, 2010, p. 61). 
O alto percentual de haver na escrita se justificaria não por ser "um reflexo de procedimentos internos à gramática nuclear, mas por provimento da gramática periférica por elementos de prestígio na língua escrita" (AVELAR, 2006b, p. 118), com a escolarização exercendo um papel fundamental na manutenção/recuperação de haver, uma vez que "no processo de letramento, a escola procura recuperar as perdas lingüísticas, uma vez que as inovações são apropriadas para a fala, mas não para a escrita" (KATO, 2005, p. 136). Haver seria um verbo existencial funcional da escrita, ainda que não rechace o uso de ter.

\section{As Sentenças com Ter, Haver e Existir no Português Brasileiro}

Ao partir do pressuposto de que o português brasileiro está passando por um processo de mudança no que se refere à marcação do Parâmetro do Sujeito Nulo, passando, assim, de uma língua [+ sujeito nulo] para [- sujeito nulo], o que teria permitido a entrada do verbo ter possessivo em contextos existenciais, Marins (2013) observa, ao longo da segunda metade do século XIX até o século XX, como se deu a implementação do verbo ter em sentenças existenciais e se a presença desse verbo teria permitido a emergência de construções existenciais que apresentam DPs plenos na posição de sujeito de ter.

Com relação à entrada de ter em contextos existenciais, a autora mostra, conforme podemos observar no Gráfico 1, que, nos quatro primeiros períodos, ter apresenta um percentual de uso baixo, chegando apenas a $9 \%$ no período III, caso que não ocorre com haver, que é o verbo existencial prototípico. É apenas a partir do período V que há uma competição acirrada entre ter e haver, chegando ter, no período VII, a 81\%. O verbo existir, por sua vez, apresenta uma frequência de uso baixa e razoavelmente constante, o que condiz com a sua qualidade de verbo existencial substantivo (Cf. AVELAR, 2006a).

A autora ainda mostra evidências que corroboram as ideias de Avelar (2006a) e Avelar e Callou (2007) de que a entrada de ter em contextos existenciais se encaixa em um conjunto mais amplo de mudanças relacionado à posição de sujeito por que vem passando o português brasileiro. Conforme podemos observar no Gráfico 2, à medida que os sujeitos pronominais de 
referência definida aparecem cada vez mais expressos (DUARTE, 1993), sobem também os percentuais de uso de ter em construções existenciais, ou seja, as construções existenciais com ter aumentam juntamente com as construções com sujeitos referenciais definidos plenos.

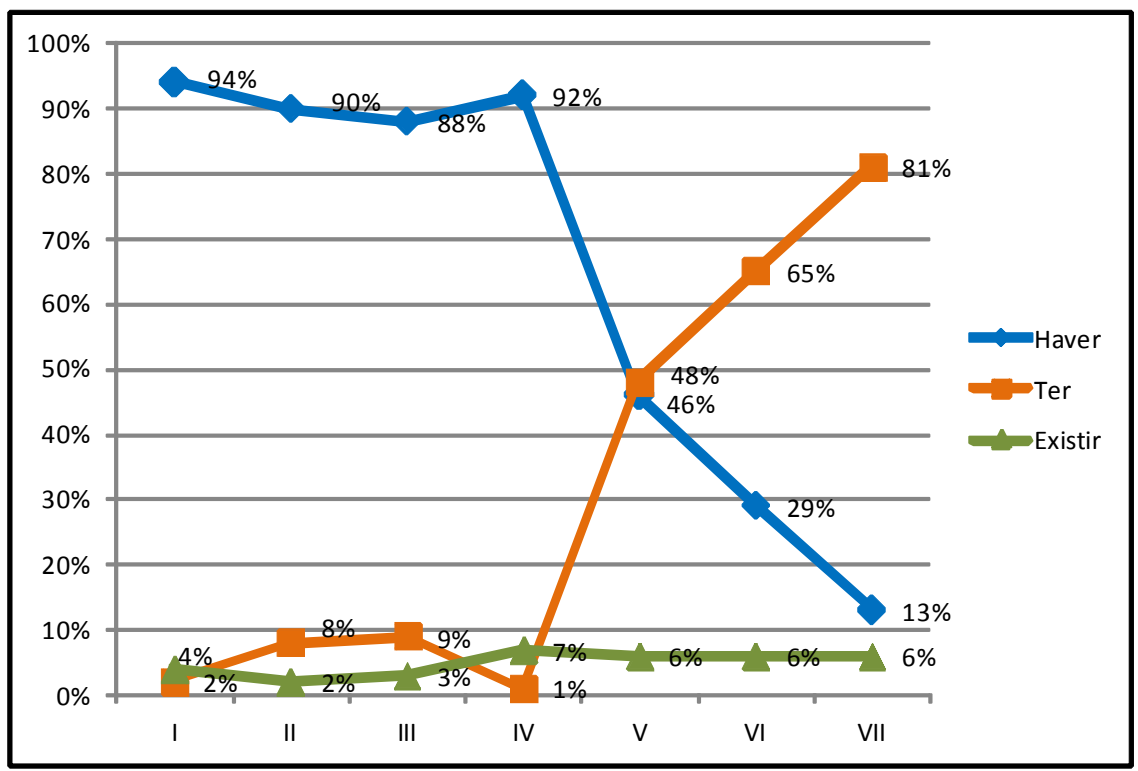

Fonte: Marins (2013, p. 61).

Gráfico 1 - Percentuais de ter, haver e existir ao longo do tempo

Ainda com relação às realizações de ter, haver e existir, Vitório (2014), tomando por base o trabalho de Avelar e Callou (2007), analisa as realizações desses verbos na fala culta alagoana com o objetivo de verificar o comportamento variável de ter e haver em construções existenciais e analisar como se comporta o verbo existir frente a essa variação, tendo em vista o seu caráter de verbo existencial substantivo no português brasileiro. De acordo com os resultados apresentados, conforme observamos no Gráfico 3, há uma predominância de ter sobre haver existir, mostrando, assim, que, na fala culta alagoana, ter é o verbo existencial preferido. 


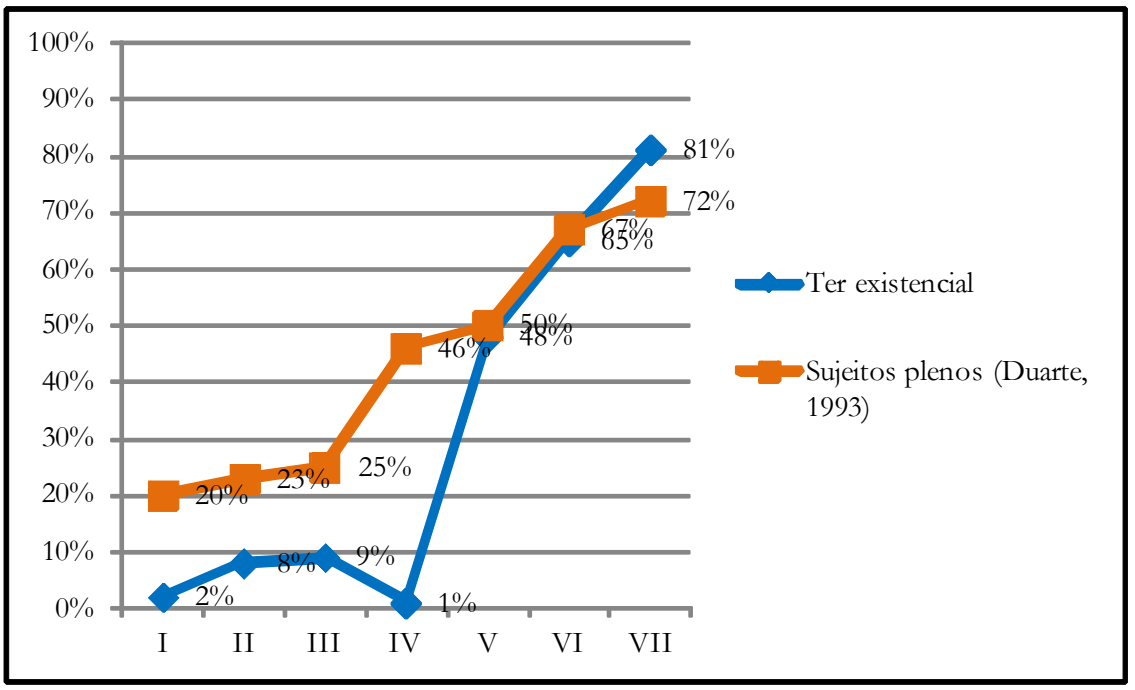

Fonte: Marins (2013, p. 62).

Gráfico 2 - Distribuição de ter vs crescimento de sujeitos de referência definida plenos

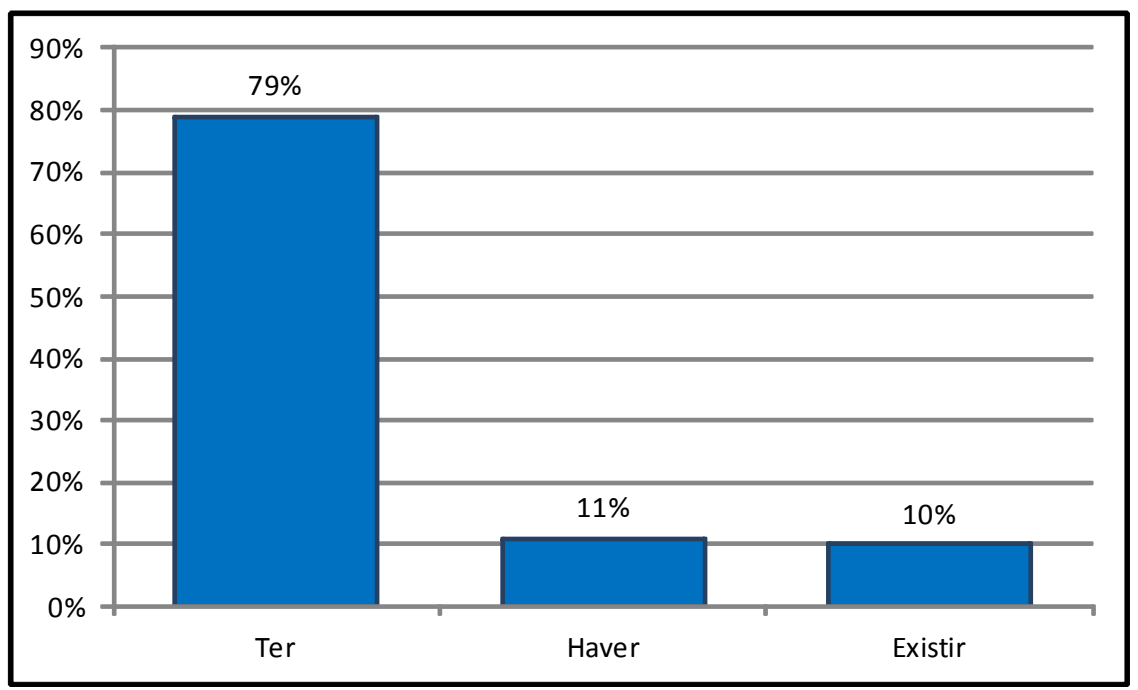

Fonte: Vitório (2014, p. 1485).

Gráfico 3 - Realizações de ter, haver e existir na fala culta alagoana 
Esses resultados, segundo Vitório (2014), mostram que ter tem trânsito livre em todos os contextos analisados. Quanto aos fatores linguísticos e sociais que ainda condicionam o uso de haver e existir, a autora pontua que haver é mais frequente quando o verbo está no passado, quando o argumento interno apresenta o traço [ + abstrato] e entre os falantes mais velhos, mostrando que, na faixa etária mais jovem - F1, haver está praticamente extinto $-2 \%$. As realizações do verbo existir, por sua vez, são restritas ao tempo presente e aos falantes das F2 e F3, revelando um percentual de 2\% na F1. Esses dados mostram que a mudança em direção ao uso de ter está quase concluída entre os falantes da F1, conforme podemos observar no gráfico abaixo.

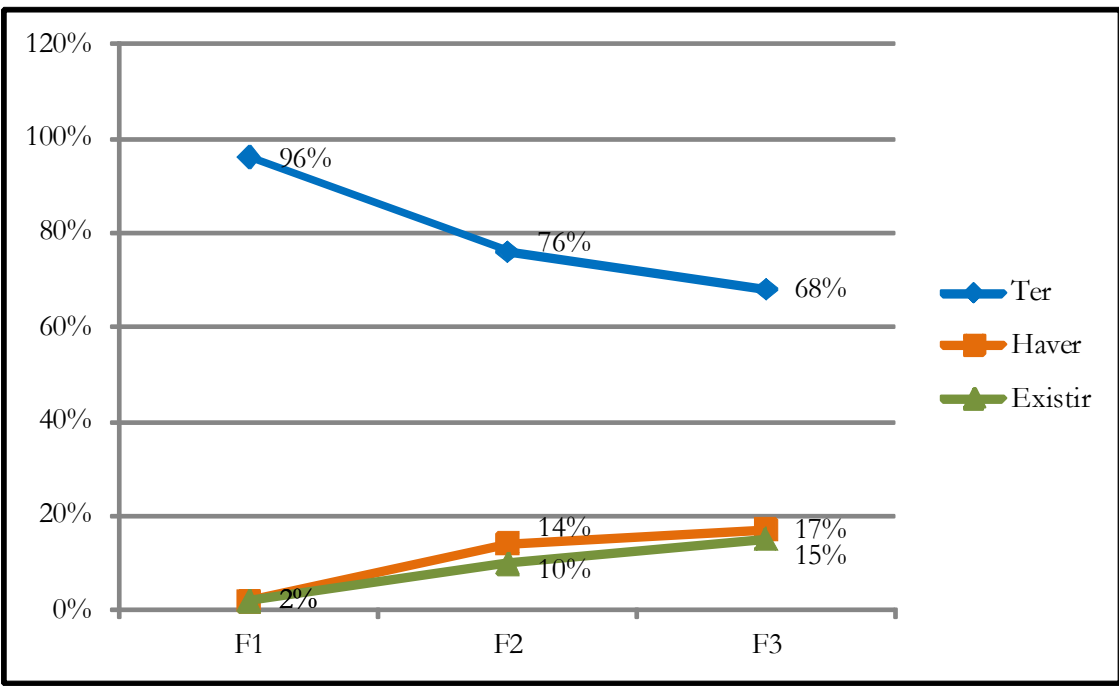

Fonte: Vitório (2014, p. 1490).

Gráfico 4 - Percentuais de ter, haver e existir na variável faixa etária

Tendo em vista esses dados, nosso foco, neste trabalho, é observar as realizações dos verbos ter, haver e existir na escrita de alunos dos ensinos fundamental, médio e superior da cidade de Maceió para verificar se as restrições encontradas na língua falada são verificadas na língua escrita e como a escola consegue manter essas formas linguísticas. Com essa análise, tentaremos mostrar qual o percurso que os usuários da língua fazem no uso 
de haver durante o processo escolar, além de verificar como se comportam os verbos ter e existir nesse contex to variável.

\section{Aporte Teórico}

Para a descrição e análise das construções existenciais formadas com os verbos ter, haver e existir na escrita de alunos dos ensinos fundamental, médio e superior da cidade de Maceió, tomamos como sustentação teórica um modelo de estudo da mudança linguística - a Teoria da Variação e Mudança (WEINREICH; LABOV; HERZOG, 2006; LABOV, 2008) associada a estudos linguísticos recentes sobre as construções existenciais no português brasileiro (AVELAR, 2006a; AVELAR; CALLOU, 2007; MARINS, 2013, VITÓRIO, 2014).

Do modelo de estudo da mudança, interessa-nos não só que a heterogeneidade linguística é ordenada, como também que toda mudança pressupõe um período de variação e, quando consolidada, produz efeitos colaterais não casuais associados ao processo de mudança - é a questão do encaixamento linguístico. Outro ponto diz respeito aos fatores que favorecem e desfavorecem dada variante durante esse processo - é a questão dos fatores condicionantes.

Dos trabalhos sobre as construções existenciais, consideramos que a implementação de ter tem relação com a remarcação do Parâmetro do Sujeito Nulo, que o teria levado a ser o existencial preferido na fala, mas, na escrita, devido à pressão normativa, haveré o existencial canônico, ocasionando uma mudança no estatuto categorial de haver, que teria passado de verbo existencial funcional a verbo existencial substantivo, como é o caso de existir, justificando a baixa frequência de uso desses verbos e suas restrições em alguns contextos.

Também consideramos a proposta de Kato (2005), que argumenta que, no português brasileiro, há um descompasso entre a gramática adquirida durante o processo de aquisição da linguagem e a gramática que orienta o ensino formal, gerando uma enorme distância entre a gramática da fala e a "gramática" da escrita, e o trabalho de Avelar (2006b) que aponta que haver seria uma forma gramatical aprendida mais tardiamente, não fazendo parte da gramática internalizada dos falantes do português brasileiro. Logo, a variação ter e haver seria "reflexo da competição entre duas gramáticas, com motivações sociolingüísticas” (AVELAR, 2006b, p. 99). 


\section{Procedimentos Metodológicos}

O que propomos é analisar a variação dos verbos ter, haver e existir na escrita de alunos dos ensinos fundamental, médio e superior da cidade de Maceió, como podemos observar nos exemplos abaixo, com o intuito de buscar evidências da implementação, na escrita, de mudanças observadas na fala e, ao mesmo tempo, refletir sobre a forma como a escrita tende a recuperar formas ausentes do processo de aquisição da linguagem.

(5) No barco tinha bebidas, almoço e uma variedade de mariscos do mar. Tinha música ao vivo. Foi incrível, espero poder voltar lá de novo. (ESM)

(6) Há casos de escolas que não começaram o ano letivo de 2012, por causa de reformas mal acabadas e quem sofre com isso são os alunos [...]. (ESF)

(7) Existe hoje educação para todos, seja em escolas particulares ou em escolas públicas, ambas deveriam fornecer aos estudantes da melhor forma possível uma educação de qualidade. (ESF)

Para a descrição e análise dos dados, utilizamos uma amostra sincrônica composta de 180 produções textuais produzidas por alunos dos ensinos fundamental, médio e superior da cidade de Maceió. As produções textuais dos alunos dos ensinos fundamental e médio foram coletadas em uma escola pública no ano de 2007 e as produções textuais dos alunos do ensino superior foram coletadas em uma faculdade particular no ano de 2012, ambas localizadas na cidade de Maceió ${ }^{2}$. Nossa amostra está estratificada de acordo com as variáveis tema da produção textual, escolaridade e sexo.

${ }^{1}$ Para representar o ensino fundamental, utilizamos textos produzidos por alunos do $9^{\circ}$ ano, para representar o ensino médio, utilizamos produções textuais de alunos do $3^{\circ}$ ano e, para representar o ensino superior, utilizamos produções textuais produzidas por alunos do $5^{\circ}$ período dos cursos de Letras, História e Biologia. Vale ressaltar que as produções textuais dos alunos do ensino superior foram produzidas por alunos que fizeram o ensino fundamental e ensino médio em escolas públicas localizadas na cidade de Maceió. 
Para a análise estatística dos dados, utilizamos o programa computacional GOLDVARB X (SANKOFF; TAGLIAMONTE; SMITH, 2005) e controlamos além da variável dependente ter, haver e existir, os seguintes grupos de fatores, a saber, tempo verbal, traço semântico do argumento interno, tema da produção textual, escolaridade e sexo.

Nossa hipótese básica é a de que o verbo haver será o existencial selecionado, ocorrendo em maior escala quando o verbo estiver no tempo passado e quando o argumento interno apresentar o traço semântico [+ abstrato], na escrita dos alunos mais escolarizados, indicando, assim, que a escola é um fator social significativo na recuperação e manutenção do verbo haver em construções existenciais, nas produções dos alunos do sexo feminino e quando o tema da produção textual não se relacionar a experiências pessoais dos alunos.

\section{Descrição e Análise dos Dados}

Após a análise dos dados, obtivemos um total de 207 realizações de ter, haver existir, que estão distribuídas da seguinte forma: 89 realizações de ter, 97 realizações de haver e 21 realizações de existir. Esses dados representam percentuais de $43 \%$ de ter, $47 \%$ de haver e $10 \%$ de existir, conforme podemos visualizar no Quadro 1 e no gráfico 5.

\begin{tabular}{|c|c|}
\hline Variável dependente & Valores obtidos \\
\hline Ter & $89-43 \%$ \\
\hline Haver & $97-47 \%$ \\
\hline Existir & $21-10 \%$ \\
\hline Total & $\mathbf{2 0 7 - 1 0 0 \%}$ \\
\hline
\end{tabular}

Fonte: A autora.

Quadro 1 - Distribuição de ter, haver e existir 


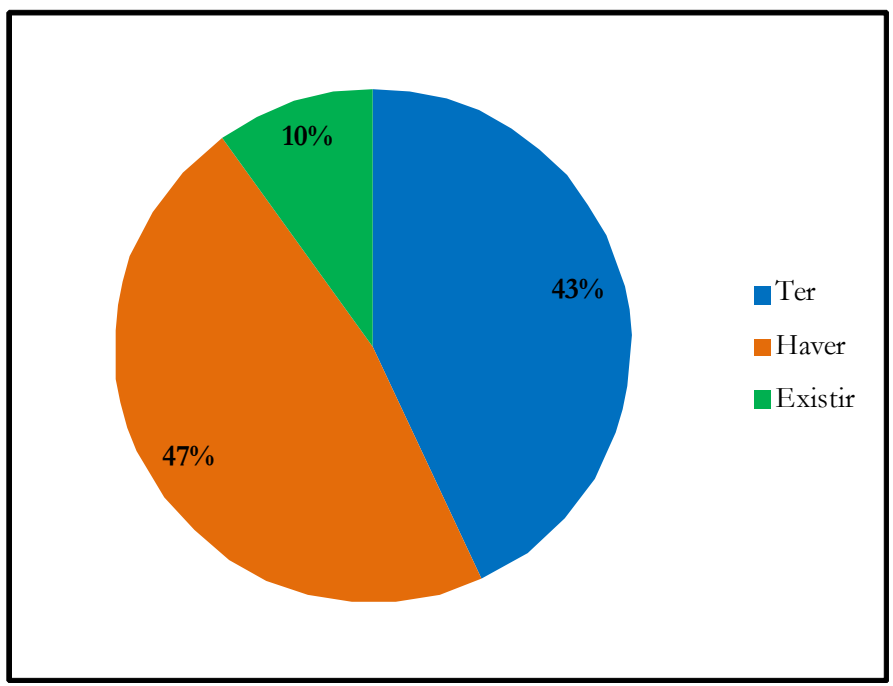

Fonte: A autora.

Gráfico 5 - Percentuais de ter, haver e existir

De acordo com os resultados obtidos, verificamos que, diferentemente do que ocorre na fala culta alagoana, em que ter é o verbo existencial preferido - $79 \%$ versus $11 \%$ de haver e 10\% de existir (Cf. VITÓRIO, 2014), na escrita escolar, apesar da pressão normativa em favor de haver, há uma competição acirrada entre ter e haver, mas é o verbo haver que apresenta um percentual maior de realização - $47 \%$ versus $43 \%$ de ter, revelando, assim, que a língua escrita tem um papel importante na recuperação e manutenção de haver, ainda que não rechace o uso de ter. No que diz respeito à realização de existir, obtivemos um percentual de 10\%, confirmando sua baixa frequência de uso, conforme pontuam Marins (2013) e Vitório (2014).

Esses resultados mostram que, na escrita escolar, há uma recuperação de uma variante quase ausente da fala, o que pode ser um indício de que haver seja um verbo existencial da escrita, passando a fazer parte do repertório linguístico dos falantes do português brasileiro a partir do processo de escolarização, mostrando, assim, uma competição entre ter e haver, que pode ser entendida como uma competição entre uma gramática inovadora vernacular e uma gramática conservadora, que se relaciona a questões sociolinguísticas e à pressão social de uso de uma norma padrão. 
Os dados obtidos parecem indicar que estamos diante de uma mudança na fala que causa efeitos na escrita, mostrando que, nesta modalidade de uso da língua, há um embate entre a gramática que falamos e a gramática que nos serve de modelo no processo de letramento. Na escrita, temos um conflito entre o que se fala e o que se aprende na escola, o que nos remete a discussão de Duarte (2013, p. 15) de que a escrita brasileira "é uma mistura de traços da gramática lusitana [...] somada a traços do português brasileiro que se implementam aos poucos na escrita, substituindo ou competindo com formas conservadoras".

Diante desses resultados, três questões emergem para possíveis interpretações dos dados, a saber: (i) em relação ao uso de ter e haver que fatores linguísticos e/ou sociais condicionam suas realizações; (ii) qual o papel da escola no que concerne às realizações de haver, e (iii) que fatores linguísticos e/ou sociais condicionam as parcas realizações de existir. Após a rodada dos dados, verificamos que apenas os grupos de fatores traço semântico do argumento interno, escolaridade e tema da produção textual foram estatisticamente relevantes para a análise dos dados ${ }^{2}$.

\subsection{Traço semântico do argumento interno}

No que diz respeito à atuação da variável traço semântico do argumento interno, estudos linguísticos (CALLOU; AVELAR, 2000; DUARTE, 2003; VITÓRIO, 2012) mostram que argumento interno com traço [+ abstrato] tende a ser um contexto mais favorável à manutenção do verbo haver em construções existenciais, enquanto que argumento interno com traço [+ concreto] tende a ser mais favorável ao uso de ter. Em nossa análise, consideramos os fatores argumento interno com traço [+ concreto] e argumento interno com traço [+ abstrato], como podemos observar em (8) e (9), e obtivemos os seguintes resultados.

(8) Uma das melhores festas que eu fui, foi a da minha prima foi o aniversário de 15 anos, foi quase toda família tinha uns familiares

2 Por trabalharmos com uma variável ternária, não apresentamos, neste trabalho, os pesos relativos para as variáveis independentes analisadas. 
que eu nem conhecia foi bom porque os conheci e revi gente que não via há 5 anos até 7 anos foi bom! (EFM)

(9) Há necessidade de melhorias no ensino e aprendizado. (ESF)

Quadro 2 - Distribuição de ter, haver e existir na variável traço semântico do argumento interno

\begin{tabular}{|c|ccc|ccc|ccc|}
\hline $\begin{array}{c}\text { Traço } \\
\text { semântico do } \\
\text { argumento } \\
\text { interno }\end{array}$ & \multicolumn{3}{|c|}{ Ter } & \multicolumn{3}{c|}{ Haver } & \multicolumn{3}{c|}{ Existir } \\
\cline { 2 - 10 } & Aplic. Total & Perc. & Aplic. Total & Perc. & Aplic. Total & Perc. \\
\hline$[+$ concreto $]$ & 46 & 77 & $60 \%$ & 27 & 77 & $35 \%$ & 4 & 77 & $5 \%$ \\
\hline$[+$ abstrato $]$ & 43 & 130 & $33 \%$ & 70 & 130 & $54 \%$ & 17 & 130 & $13 \%$ \\
\hline
\end{tabular}

Fonte: A autora.

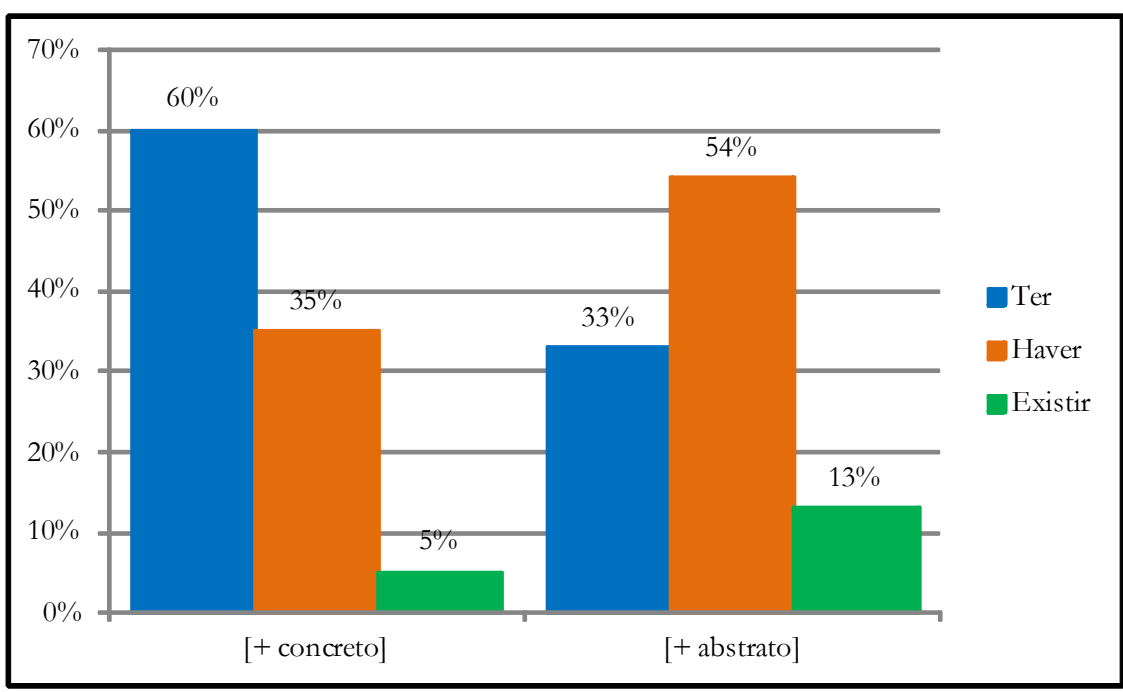

Fonte: A autora.

Gráfico 6 - Percentuais de ter, haver e existir na variável traço semântico do argumento interno 
De acordo com os resultados obtidos, verificamos, em consonância com o que esperávamos, que as frequências de uso de tere haver em construções existenciais na escrita escolar são diametralmente opostas em relação ao traço semântico do argumento interno. Quando o argumento interno é do tipo [+ concreto], temos um percentual maior de realização do verbo ter $-60 \%$ versus 35\% de haver, como observamos em (10), mas quando o argumento interno é do tipo [+ abstrato], haver apresenta um percentual maior de realização - 54\% versus 33\% de ter, conforme podemos observar em (11), mostrando ser esse fator mais favorável à manutenção e recuperação de haver nos dados analisados.

(10) Até mesmo a sociedade tem um pouco de preconceito, quando tem uma turma conversando e no meio tem alguém que estuda na rede pública fica toda sem jeito, sem assunto e quando os da particular ficam sabendo que esta pessoa estuda na pública já olha meio de lado. (ESF)

(11) No dia 10/06/07 foi meu aniversário e no mesmo dia o meu irmão tinha feito um encontro, no qual quando ele chegou em casa houve uma recepção, então comemoramos o meu aniversário e a recepção dele no mesmo dia. (EFF)

O verbo existir, por sua vez, conforme podemos observar, apresenta um percentual de uso baixo e constante - 5\% quando o argumento interno é do tipo [+ concreto] e 13\% quando o argumento interno é do tipo [+ abstrato], conforme podemos observar nos exemplos (12) e (13).

(12) Mas, por ser uma matéria um pouco complicada, existem pessoas que ainda usam de forma errada, no seu dia a dia, seja na escola, no trabalho, nas ruas, em casa, e até mesmo em outros lugares (EFF)

(13) Era engraçado observar a harmonia que existia naquele lugar: as pessoas caminhavam, as crianças brincavam, os idosos cochilavam, os coqueiros balançavam e alguns, como eu, só observavam. (ESM) 


\subsection{Escolaridade}

Em relação à atuação da variável escolaridade, partimos do pressuposto de que essa variável constitui um fator social significativo na manutenção ou exclusão de formas gramaticais, mostrando, assim, que pessoas mais escolarizadas tendem a usar mais as formas padrão de uso da língua, o que nos leva a seguinte correlação: maior escolaridade, maior uso das formas padrão; menor escolaridade, menor uso das formas padrão.

A observação do dia-a-dia confirma que a escola gera mudanças na fala e na escrita das pessoas que as frequentam e das comunidades discursivas. [...]. Compreende-se, nesse contexto, a influência da variável nível de escolarização, ou escolaridade, como correlata aos mecanismos de promoção ou resistência à mudança. (VOTRE, 2003, p. 51).

Dessa forma, acreditamos que haver, como podemos observar em (14) e (15), aumentará o seu percentual de uso à medida que aumenta o nível de escolarização dos alunos. Para tanto, consideramos três níveis de escolarização, a saber, ensino fundamental (EF), ensino médio (EM) e ensino superior (ES) e obtivemos os seguintes resultados.

(14) Há pessoas sofrendo, sendo humilhadas por falta de um bom ensino. Até quando teremos que assistir tanta catástrofe no Brasil. Esse é meu desabafo. (ESM)

(15) As escolas particulares atribuem um bom desempenho para a educação de seus alunos, dando aos mesmos direito. Há material adequado, boa higiene e conforto para que essas pessoas sintam o prazer de estar ali [...]. (ESF)

De acordo com os resultados obtidos, verificamos que, com o aumento do nível de escolarização dos alunos, o verbo haver aumenta o seu percentual de uso, atingindo, na escrita dos alunos do ES, um percentual de $60 \%$. Na escrita dos alunos do EF, ter é o verbo existencial selecionado, apresentando, assim, um percentual de uso de 71\%, mas, na escrita dos alunos do EM, temos uma competição acirrada entre os verbos ter e haver $-47 \%$ 
versus $44 \%$, respectivamente. No que se refere ao uso de existir, obtivemos taxas de uso mais ou menos constantes e baixas, não ultrapassando os $12 \%$, o que confirma sua baixa frequência de uso, conforme pontuam Marins (2013) e Vitório (2014). Esses percentuais parecem refletir o fato de existir, de acordo com a proposta de Avelar (2006a), ser um verbo existencial substantivo, sendo, assim, pouco frequente no português brasileiro.

Quadro 3 - Distribuição de ter, haver e existir na variável escolaridade

\begin{tabular}{|c|ccc|ccc|ccc|}
\hline \multirow{2}{*}{ Escolaridade } & \multicolumn{3}{|c|}{ Ter } & \multicolumn{3}{c|}{ Haver } & \multicolumn{3}{c|}{ Existir } \\
\cline { 2 - 10 } & Aplic. Total & Perc. & Aplic. Total & Perc. & Aplic. Total & Perc. \\
\hline EF & 38 & 54 & $71 \%$ & 12 & 54 & $22 \%$ & 4 & 54 & $7 \%$ \\
\hline EM & 21 & 45 & $47 \%$ & 20 & 45 & $44 \%$ & 4 & 45 & $9 \%$ \\
\hline ES & 30 & 108 & $28 \%$ & 65 & 108 & $60 \%$ & 13 & 108 & $12 \%$ \\
\hline
\end{tabular}

Fonte: A autora.

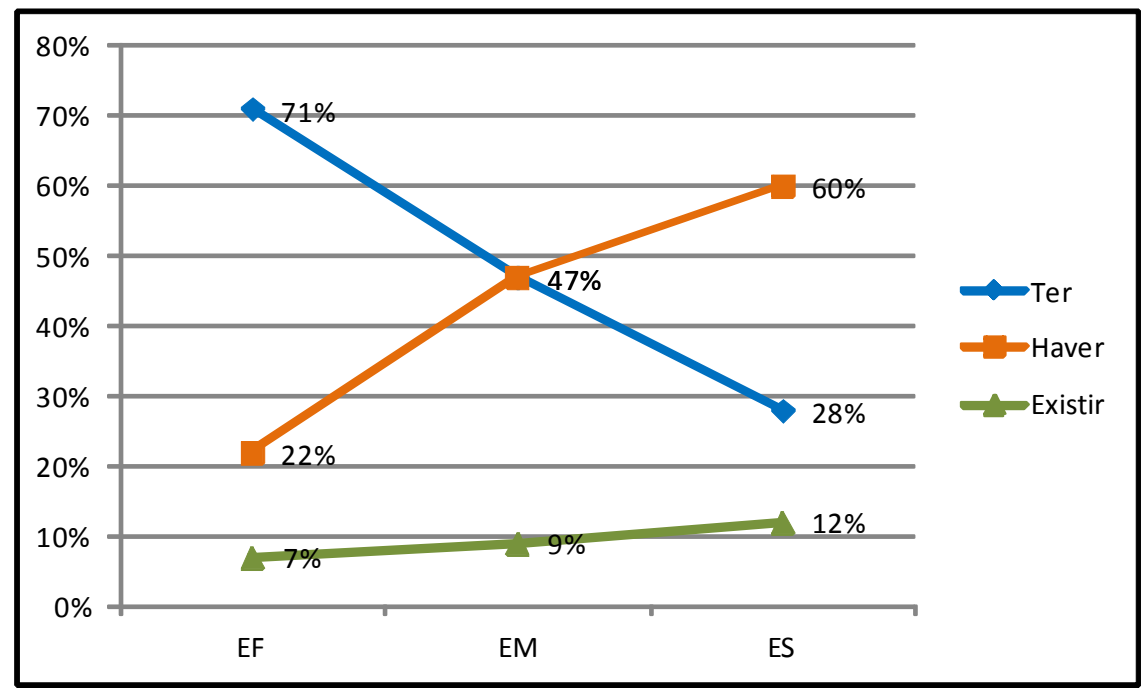

Fonte: A autora.

Gráfico 7 - Percentuais de ter, haver e existir na variável escolaridade 
Esses resultados mostram, como já esperávamos, que a variável escolaridade constitui um fator social significativo na recuperação e manutenção do verbo haver em construções existenciais, mostrando, assim, que, no início do processo de escolarização, os alunos transferem o seu conhecimento gramatical da fala para a escrita e é a submissão às regras gramaticais que faz com que o verbo haver, ausente na fala de crianças em início de atividade escolar (Cf. VITÓRIO, 2010), apareça na escrita e aumente o seu percentual de uso à medida que aumenta o nível de escolarização dos alunos, chegando a superar o uso de ter na escrita de alunos do ES. O que revela produções textuais recheadas por uma mistura de formas variantes.

A criança que já passou pelo processo de aquisição, vem para a escola com um conhecimento gramatical de língua nativa (Língua-I) pronta, e muitas vezes, ao chegar à escola, é apresentada a formas que não correspondem àquelas que ela adquiriu. Mesmo diante de formas diferentes, a criança vai utilizar o conhecimento de que já dispõe e a escola vai tentar reprimir esse uso através das correções, pois ele não condiz com aquele exigido pela Gramática Normativa $(\mathrm{GN})$ para a escrita. Como consequência, teremos produções escritas recheadas por uma mistura de formas que reflete o conhecimento da gramática que o aluno traz para a escola (sua gramática-I) e das regras que lhe são ensinadas durante o processo de ensino-aprendizagem. (MAGALHÃES, 2000, p. 43).

A atuação da variável escolaridade na recuperação e manutenção do verbo haver na língua escrita é ainda mais evidente ao compararmos os percentuais aqui obtidos com os resultados apresentados em Vitório (2007), conforme podemos observar no Gráfico 8. De acordo com os dados obtidos, verificamos que o acesso às regras gramaticais é determinante na escolha dessa variante, pois seu uso aumenta à medida que aumenta o nível de escolarização dos alunos, passando de $9 \%$ nos textos dos alunos do $6^{\circ}$ ano do EF para $60 \%$ nos textos dos alunos do ES, ou seja, quanto mais escolarizado o aluno, maior o percentual de uso de haver na escrita. 


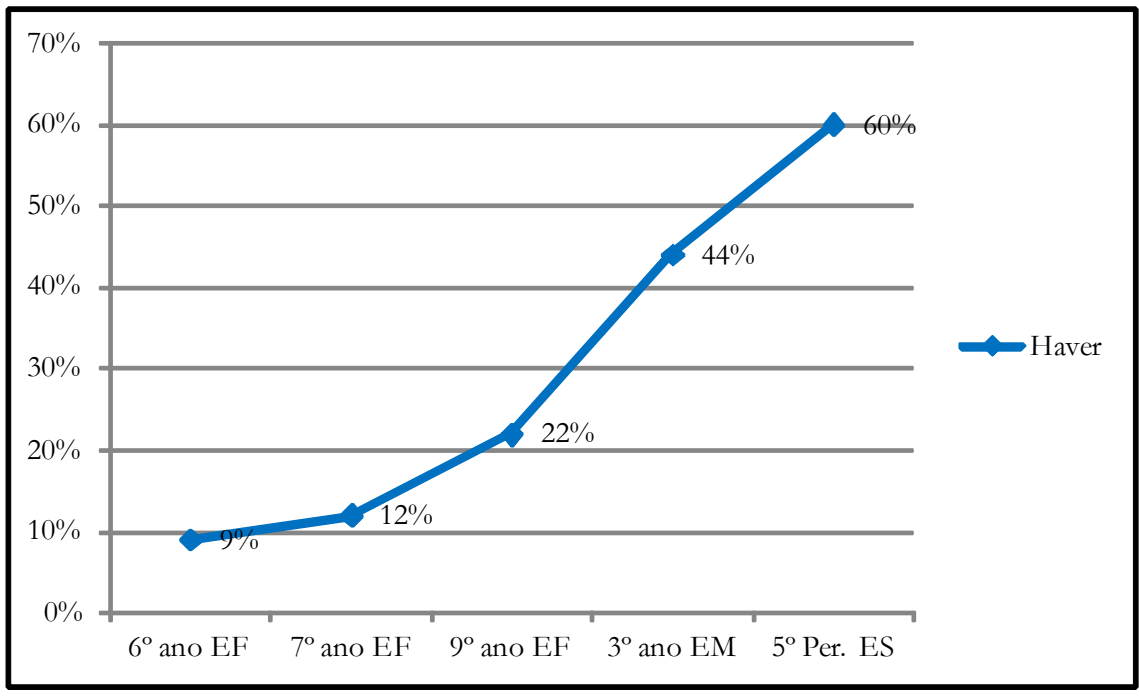

Fonte: A autora.

Gráfico 8-Percentuais de haver em diferentes níveis de escolarização

Esses dados parecem indicar que as produções textuais dos alunos das séries iniciais refletem a gramática adquirida durante o processo de aquisição da linguagem, que seleciona ter como existencial canônico (Cf. VITÓRIO, 2010), o que nos mostra que os alunos levam para escrita a variante utilizada na fala - ter, mas, com o aumento do nível de escolarização, há um aumento no uso de haver, revelando, assim, que a escola exerce um papel preponderante na recuperação e manutenção de haver. No entanto, são necessários muitos anos de escolarização para que o aluno use, de fato, as regras prescritas pela tradição escolar.

\subsection{Tema da produção textual}

No que se refere à atuação da variável tema da produção textual, consideramos, de acordo com Labov (2008), que não existe falante de estilo único, há falantes que possuem um campo de alternância mais amplo do que o outro, porém todos modificam algumas variáveis à medida que muda o contexto social e o tema da conversa. O autor ainda ressalta que temas que relatam experiências vividas pelos informantes tendem a apresentar um 
discurso mais livre e espontâneo, favorecendo, assim, o uso de variantes inovadoras.

Em nossa análise, controlamos os seguintes fatores, a saber, temas relacionados a experiências pessoais dos alunos e temas não relacionados a experiências pessoais dos alunos e partimos do pressuposto de que este fator é mais favorável ao uso de haver do que aquele. O Quadro 4 e o Gráfico 9 ilustram os resultados obtidos para esta variável.

Quadro 4 - Distribuição de ter, haver e existir na variável tema da produção textual

\begin{tabular}{|c|ccc|ccc|ccc|}
\hline $\begin{array}{c}\text { Tema da } \\
\text { produção } \\
\text { textual }\end{array}$ & \multicolumn{3}{|c|}{ Ter } & \multicolumn{3}{c|}{ Haver } & \multicolumn{3}{c|}{ Existir } \\
\cline { 2 - 9 } & Aplic. Total & Perc. & Aplic. Total & Perc. & Aplic. Total & Perc. \\
\hline $\begin{array}{c}\text { Experiências } \\
\text { pessoais }\end{array}$ & 46 & 84 & $55 \%$ & 34 & 84 & $40 \%$ & 4 & 84 & $5 \%$ \\
\hline $\begin{array}{c}\text { Experiências } \\
\text { não textuais }\end{array}$ & 43 & 123 & $35 \%$ & 63 & 123 & $51 \%$ & 17 & 123 & $14 \%$ \\
\hline
\end{tabular}

Fonte: A autora.

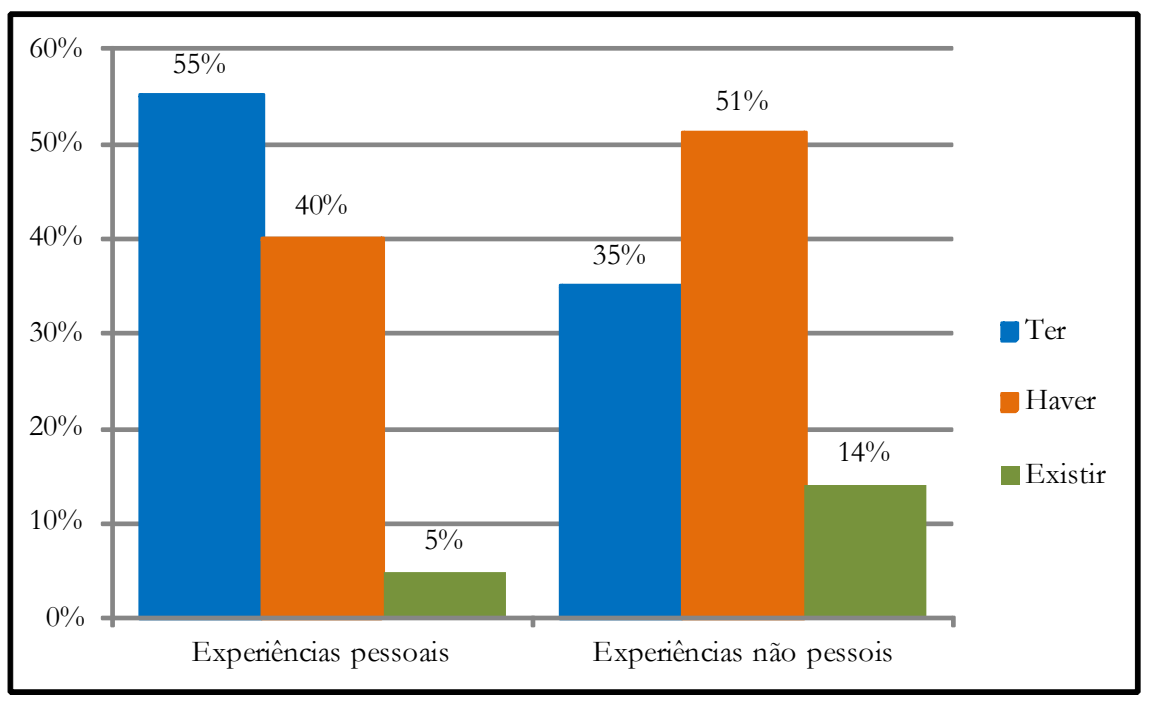

Fonte: A autora.

Gráfico 9 - Percentuais de ter, haver e existir na variável tema da produção textual 
De acordo com resultados obtidos, verificamos que as realizações de ter e haver são diametralmente opostas em relação ao tema da produção textual. Quando o tema da produção textual está relacionado a experiências pessoais dos alunos, como podemos observar em (16), o verbo ter apresenta um percentual maior de realização - $55 \%$ versus $40 \%$ de haver, quando o tema da produção textual não se refere a experiências pessoais dos alunos, como podemos observar em (17), haver é o verbo existencial mais frequente - $51 \%$ versus $35 \%$ de ter.

(16) Uma das melhores festas que eu fui foi a da minha prima foi o aniversário de 15 anos, foi quase toda família tinha uns familiares que eu nem conheci foi bom porque os conheci e revi gente que não via há 5 anos até 7 anos foi bom! (EFM)

(17) Há uma grande diferença entre educação no setor privado (excelentes) e no setor público (péssimo). Nós cidadãos pagamos caro pela nossa educação, já que nossos governantes nada fazem, pois seus filhos estudam no exterior e eles não estão nem aí para a população. (ESM)

Em relação ao uso do verbo existir, apesar de suas parcas realizações, também verificamos que o seu percentual de uso aumenta quando o tema da produção textual não tem relação com as experiências pessoais dos alunos, passando de 5\% quando o tema da produção textual se relaciona a experiências pessoais dos alunos para $14 \%$ nas produções textuais que não relatam tais experiências, como podemos observar em (18) e (19), respectivamente.

(18) A praia do francês não é só praia e sim tem artesanatos, que existem diversos tipos de coisas que agradam toda a clientela quem a visita e a sua culinária que deixa o turista e os da casa com água na boca, tipicamente alagoana [...]. (ESM)

(19) Existe hoje educação para todos, seja em escolas particulares ou em escolas públicas, ambas deveriam fornecer aos estudantes da melhor forma possível uma educação de qualidade. (ESF) 
Embora os textos em análise tenham sido produzidos por alunos mediante certo grau de atenção à escrita, tendo em vista o contexto escolar, esses resultados fornecem evidências de que quando o tema da produção textual está relacionado a experiências pessoais dos alunos, há um menor monitoramento, favorecendo mais o uso da variante inovadora ter, ao passo que quando o tema da produção textual não se refere a experiências pessoais dos alunos, há um monitoramento maior, o que favorece mais o uso da variante conservadora haver e aumenta o percentual de uso de existir, corroborando a hipótese de Labov (2008) de que os informantes, ao relatarem experiências vividas, tendem a apresentar um discurso mais livre e espontâneo, favorecendo, assim, as realizações de variantes inovadoras.

\section{Conclusão}

Neste trabalho, focalizamos as realizações dos verbos ter, haver existir na escrita de alunos dos ensinos fundamental, médio e superior da cidade de Maceió, com o intuito de analisar a frequência de uso dessas construções e os grupos de fatores linguísticos e sociais que condicionam tais realizações. De acordo com os resultados obtidos, verificamos que há uma competição acirrada entre ter e haver - 43\% versus 47\%, respectivamente, e uma baixa frequência de uso de existir - 10\%, sendo essa variação favorecida pelas variáveis traço semântico do argumento interno, escolaridade e tema da produção textual.

$\mathrm{O}$ verbo ter apresenta um percentual maior de realização quando o argumento interno apresenta o traço [+ concreto], na escrita de alunos menos escolarizados e nas produções textuais que relatam experiências pessoais vividas pelos alunos. O verbo haver, por sua vez, é mais frequente quando o argumento interno é do tipo [+ abstrato], na escrita de alunos mais escolarizados, indicando, assim, que, com o aumento da escolarização, há um aumento no seu percentual de uso e nas produções textuais dos alunos que não relatam tais experiências.

Em relação ao uso do verbo existir, verificamos um percentual de uso baixo e constante, conforme pontuam Marins (2013) e Vitório (2014), o que pode estar relacionado ao seu caráter de verbo existencial substantivo (Cf. AVELAR, 2006a). No entanto, alguns fatores contribuem para aumentar 
a sua frequência de uso, a saber, argumento interno que apresenta o traço [+ abstrato], aumento do nível de escolarização dos alunos e produções textuais que não relatam experiências pessoais dos alunos.

Os resultados aqui obtidos mostram que, na escrita escolar, a pressão normativa em favor de haver existencial coloca essa variante em primeiro lugar, recuperando com êxito uma forma linguística tão distante da língua falada, o que nos leva a discussão de que a variação ter e haver no português brasileiro pode ser vista como uma competição entre duas gramáticas: uma gramática da fala que seleciona ter e uma gramática da escrita que não só elege haver, mas também implementa nos textos escritos formas linguísticas não prescritas pela tradição gramatical, como é o caso do verbo ter.

\section{Referências}

AVELAR, J. De verbo funcional a verbo substantivo: uma hipótese para a supressão de haver no português brasileiro. Letras de Hoje, v. 41, n. 1, p. 49-74, 2006a.

AVELAR, J. Gramática, competição e padrões de variação: casos com ter/haver e de/em no português brasileiro. Revista de Estudos da Linguagem, n. 4, p. 99-144, 2006b.

AVELAR, J; CALLOU, D. Sobre a emergência do verbo possessivo em contextos existenciais no português brasileiro. In: CASTILHO, A. et al. (Orgs.). Descrição, história e aquisição do português brasileiro. São Paulo: Pontes, 2007. p. 375-402.

CALLOU, D.; AVELAR, J. Sobre ter e haver em construções existenciais: variação e mudança no português do Brasil. Revista Gragoatá, n. 9, p. $85-100,2000$.

CALLOU, D.; DUARTE, M. E. L. A fixação do verbo ter em contextos existenciais. In: ENCONTRO NACIONAL DA ASSOCIAÇÃO PORTUGUESA DE LINGUÍSTICA, 20., 2005, Lisboa. Actas... Lisboa: APL, 2005. 
DUARTE, E. Do pronome nulo ao pronome pleno: a trajetória do sujeito no português do Brasil. In: ROBERTS, I.; KATO, M. Português brasileiro: uma viagem diacrônica. Campinas: Editora da Unicamp, 1993. p. 107-128.

DUARTE, E. O sujeito expletivo e as construções existenciais. In: RONCARATI, C.; ABRAÇADO, J. (Orgs.). Português brasileiro: contato lingüístico, heterogeneidade e história. São Paulo: 7 Letras, 2003. p. 123-131.

DUARTE, E. O papel da sociolinguística no (re)conhecimento do português brasileiro e suas implicações para o ensino. Revista LETRA, p. 15-10, 2013.

KATO, M. Português brasileiro falado: aquisição em contexto de mudança lingüística. In: DUARTE, I.; LEIRIA, I. (Orgs.). Actas do Congresso Internacional sobre o Português. v. II. 1996. p. 211-237.

KATO, M. A gramática do letrado: questões para a teoria gramatical. In: MARQUES, M. et al. (Orgs.). Ciências da linguagem: trinta anos de investigação e ensino. Braga: CEHUM (U. do Minho), 2005. p. 131-145.

LABOV, W. Padrões sociolingüísticos. São Paulo: Parábola, 2008 [1972].

MAGALHÃES, T. Aprendendo o sujeito nulo na escola. 2000. Dissertação (Mestrado em Linguística) - Universidade Estadual de Campinas, Campinas.

MARINS, J. As repercussões da remarcação do Parâmetro do Sujeito Nulo: um estudo diacrônico das sentenças existenciais com ter e haver no PB e no PE. 2013. Tese (Doutorado em Letras Vernáculas) - Universidade Federal do Rio de Janeiro, Rio de Janeiro.

MARTINS, L.; CALLOU, D. Mudança em tempo aparente e em tempo real: construções ter/haver existenciais. In: ENCONTRO DO CELSUL, 5., 2003, Curitiba. Anais... Curitiba: CELSUL, 2003. p. 820-825. 
SANKOFF, D.; TAGLIAMONTE, S,; SMITH, E. Goldvarb X: a variable rule application for Macintosh and Windows. 2005. Department of Linguistics, University of Toronto.

VITÓRIO, E. Ter/haver existenciais na escrita de alunos de $5^{\mathrm{a}}$ e $6^{\mathrm{a}}$ séries do ensino fundamental da cidade de Maracanaú/CE. Revista Virtual de Estudos da Linguagem - ReVEL, v. 5, n. 9, p. 1-17, 2007.

VITÓRIO, E. Um estudo sobre a variação ter e haver existenciais na escrita de alunos dos ensinos fundamental e médio da cidade de Maceió. Revista Eletrônica Via Litterae, v. 2, n. 1, p. 75-87, jan./jun. 2010.

VITÓRIO, E. Ter/ haver existenciais na fala alagoana: variação estável ou mudança em progresso? 2012. Tese (Doutorado em Linguística) Universidade Federal de Alagoas, Maceió.

VITÓRIO, E. As construções existenciais na fala e na escrita. Diadorim, Rio de Janeiro, v. 14, p. 53-76, dez. 2013.

VITÓRIO, E. A substituição de haver por ter em contextos existenciais: ecos da mudança na remarcação do Parâmetro do Sujeito Nulo. In: CONGRESSO INTERNACIONAL ASOCIACIÓN DE LINGUÍSTICA Y FILOLOGIA DE AMÉRICA LATINA, 17., João Pessoa, 2014. Anais.. João Pessoa: ALFAL, 2014. p. 1481-1492.

VOTRE, S. Relevância da variável escolaridade. In: MOLLICA, C.; BRAGA, L. (Orgs.). Introdução à Sociolingüistica: o tratamento da variação. São Paulo: Contexto, 2003. p. 51-58.

WEINREICH, U.; LABOV, W.; HERZOG, M. Fundamentos empíricos para uma teoria da mudança lingüistica. São Paulo: Parábola, 2006 [1968]. 